\title{
THROMBOCYTE ESTIMATION BASED ON BLOOD SMEAR AND ITS COMPARISON USING AUTOMATED HAEMATOLOGY ANALYSERS
}

\author{
Abdul Mabood ${ }^{1}$, Vineet Chaturvedi², Shalini Gupta ${ }^{3}$, M. Qamar Alam4, Neetu Dwivedi5, Savita Agarwal6, Pinki Pandey ${ }^{7}$ \\ 1Junior Resident, Department of Pathology, Uttar Pradesh University of Medical Sciences, Saifai, Uttar Pradesh, India. \\ ${ }^{2}$ Associate Professor, Department of Pathology, Uttar Pradesh University of Medical Sciences, Saifai, Uttar Pradesh, India. \\ 3Junior Resident, Department of Pathology, Uttar Pradesh University of Medical Sciences, Saifai, Uttar Pradesh, India. \\ 4Junior Resident, Department of Pathology, Uttar Pradesh University of Medical Sciences, Saifai, Uttar Pradesh, India. \\ 5Junior Resident, Department of Pathology, Uttar Pradesh University of Medical Sciences, Saifai, Uttar Pradesh, India. \\ ${ }^{6}$ Associate Professor, Department of Pathology, Uttar Pradesh University of Medical Sciences, Saifai, Uttar Pradesh, India. \\ ${ }^{7}$ Professor, Department of Pathology, Uttar Pradesh University of Medical Sciences, Saifai, Uttar Pradesh, India.
}

\section{BACKGROUND}

ABSTRACT

Accurate platelet counts are very important and are essential for patient care. There are many methods for counting platelets. Study was conducted with the objectives of evaluation of thrombocyte count from peripheral blood smear (PBS) and by using Sysmex automated haematology analyser and to compare the precision of manual method in comparison to automated platelet counts. Evaluation of thrombocyte counts is very necessary for certain conditions like dengue hemorrhagic fever. Thrombocyte counts are considered as one of the most important parameters to assess the severity of the illness and also to monitor the progression of the illness and response to the treatment. In such critical situations, manual counting of thrombocytes is considered more reliable compared to automated analysers. Automated haematology analyser counters are not usually available at all centres, especially in peripheral and rural areas though thrombocytes can also be assessed from the peripheral blood smears, which can be easily and precisely done at any set up.

\section{METHODS}

A study was conducted on 1000 Ethylene Diamine Tetra Acetic Acid (EDTA) anticoagulated blood samples taken between October 2017 to May 2018. Samples were evaluated by automated haematology analyser (Sysmex XN1000 series), using impedance counting method and by examination of peripheral blood smear using Leishman's stain supplied by Sisco Research Laboratories Pvt Ltd. The calculation was done by determining the average number of platelets in an oil immersion field after assessing at least 10 fields of each peripheral blood smear in an oil immersion field.

\section{RESULTS}

Two sample $t$ tests showed no significant difference between the two methods. Pearson correlation of the two methods showed high correlation.

\section{CONCLUSIONS}

Thrombocyte estimation done manually using PBS is not significantly different from thrombocyte estimated by the automated haematology analyser. Manually done thrombocyte count using PBS can be taken as a simple and rapid method for thrombocyte evaluation in patients where low thrombocyte count needs an early and immediate attention. This method is simple, rapid as well as cheaper thus can be done even in centres where automated analysers are not available. All the abnormally low or high thrombocyte counts on automated counter must be cross examined manually before being reported.

HOW TO CITE THIS ARTICLE: Mabood A, Chaturvedi V, Gupta S, et al. Thrombocyte estimation based on blood smear and its comparison using automated haematology analysers. J. Evolution Med. Dent. Sci. 2019;8(19):1588-1591, D0I: $10.14260 /$ jemds/2019/351

\section{BACKGROUND}

Thrombocytes in blood play a very important role in haemostasis. ${ }^{1}$ The normal range usually between 150000 $400000 / \mu \mathrm{L}^{2}$ The life span of a thrombocyte varies between 7-12 days normally. ${ }^{3}$ In peripheral blood thrombocytes show great variation morphologically with respect to features like size, density, and staining properties. ${ }^{4}$

'Financial or Other Competing Interest': None.

Submission 20-03-2019, Peer Review 24-04-2019,

Acceptance 30-04-2019, Published 13-05-2019.

Corresponding Author:

Dr. Vineet Chaturvedi,

Associate Professor, Department of Pathology,

Uttar Pradesh University of Medical Sciences,

Saifai, Etawah-206130,

Uttar Pradesh, India.

E-mail: vinch555@yahoo.in

DOI: $10.14260 /$ jemds $/ 2019 / 351$
Different methods of thrombocyte estimation along with type of anticoagulant used have impact on the morphology of thrombocytes accordingly. ${ }^{5}$ Granules which are Azurophilic also seen in light blue cytoplasm. ${ }^{6}$ Thrombocytes are very important component of our blood play significant role in many physiological processes along definitive roles in haemostasis and thrombosis. ${ }^{7}$

Automated haematology analysers produce erroneous results in the presence of particles of similar size and shape and in the presence of giant platelets and platelet clumps. ${ }^{8}$ In patients with severe thrombocytopenia obtaining accurate and precise thrombocyte counts by automated haematology analysers is still challenging especially when important clinical decision has to be made regarding thrombocyte transfusion. Until recently results of the International Biomedical Excellence for Safer Transfusion Collaborative study clearly indicate that significant inaccuracy exists when counting low levels of thrombocytes using automated 
haematology analysers. This inaccuracy might lead to over or under-transfusion of thrombocyte concentrates in high-risk patients of bleeding. ${ }^{9}$

In infections like malaria and dengue thrombocytopenic patients facing the potential risk of bleeding an accurate thrombocyte count is of vital importance. Thrombocyte count is also one of the parameters to assess the severity of dengue. 10 It is also important to forecast patients undergoing cytotoxic therapy for haematological malignancies. Studies have shown that thrombocyte count is often reduced than normal in patients of Non-alcoholic fatty liver disease (NAFLD), thereby providing a supportive indicator in addition to liver biopsy in these patients. At present, thrombocyte count is also used for prognostication of fibrosis and cirrhosis of the liver. ${ }^{11}$ So it is of prime importance for laboratories to evaluate thrombocytes with utmost precision.

The common methods usually in practice for thrombocyte estimation are-

1. Manual method using counting chamber like Improved Neubauer chamber.

2. Estimation using Leishman stained peripheral blood smears.

3. Estimation using the automated haematology analysers.

\section{Aim of The Study}

To compare the results of manual platelet counts on PBS to that of hematology analyser.

\section{METHODS}

The present study was a comparative diagnostic study done in Department of Pathology, Uttar Pradesh University of Medical Sciences, Saifai, Etawah, Uttar Pradesh, India from October 2017 to May 2018. A total of 1000 samples assessed for thrombocytes. Sample size was taken based on the convenience of the study.

\section{Inclusion Criteria}

All properly labelled samples of patients which were received in EDTA anticoagulant in the laboratory for thrombocyte count are taken for evaluation.

\section{Exclusion Criteria}

\begin{tabular}{lccr} 
Samples & which & were & \multicolumn{2}{r}{ improperly } \\
labelled/haemolysed/clotted & were & excluded & from
\end{tabular} assessment.

EDTA samples received in the laboratory were evaluated by two techniques-

1. Automated Platelet Count: Platelets were analysed in automated haematology counters by using Sysmex XP1000 series.

2. Assessment of Platelet Count on Leishman's Stained (LS) peripheral blood smears.

Smears were stained with LS as per standard protocol. Thrombocytes are counted in the ideal zone of a smear stained with LS where there is fairly proportionate distribution of leucocytes and thrombocytes. The estimation is done by using the average number of thrombocytes in a high power (Oil immersion field) multiplied by factor of 15 thousand. 9,10 Assessment of at least 10 fields is to be done, each thrombocyte in an average high-power field (Oil immersion field) represents 15000 platelets/cu mm. ${ }^{10}$

\begin{tabular}{|c|c|c|}
\hline & $\begin{array}{c}\text { Automated } \\
\text { Analyser }\end{array}$ & $\begin{array}{c}\text { Manual } \\
\text { Method }\end{array}$ \\
\hline Mean Platelet Count & $307 \times 10^{3} / \mu \mathrm{L}$ & $310 \times 10^{3} / \mu \mathrm{L}$ \\
\hline $\mathrm{p}$ Value & \multicolumn{2}{|c|}{ Less than 0.001} \\
\hline Pearson Correlation & \multicolumn{2}{|c|}{0.978} \\
\hline $\begin{array}{c}\text { Table 1. Correlation Between Automated Analyser and } \\
\text { Manual Method of Platelet Estimation }\end{array}$ \\
\hline
\end{tabular}
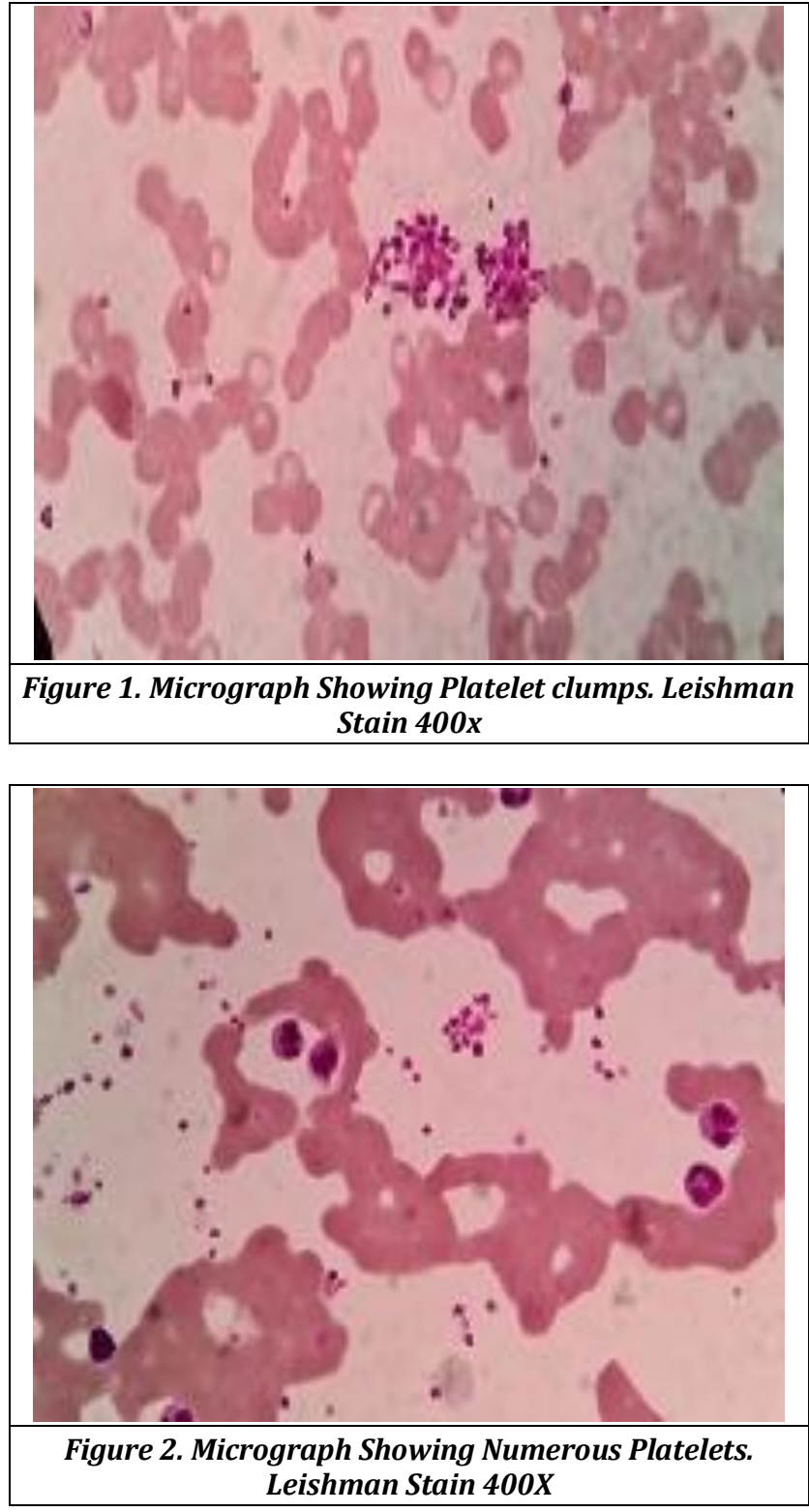

\section{Statistical Analysis}

Data was coded into MS Excel and analysed using SPSS programme v17. Average thrombocytes estimated using mean and standard deviation. Significant difference among mean thrombocyte count was estimated using independent sample $t$ test. The correlation between automated thrombocyte count and manual method was studied using Pearson correlation. $\mathrm{P}$ value less than 0.05 is considered statistically significant.

\section{RESULTS}

Automated Thrombocyte count done in this study had a mean value of 3.07 Lacs/ uL and standard deviation of $0.7 \mathrm{Lacs} / \mathrm{uL}$. 
Thrombocyte count estimated by the manual method used in this study had the mean value of $3.10 \mathrm{Lacs} / \mathrm{uL}$ and standard deviation of 1.10 Lacs/ uL. P value $<0.001$ was considered as statistically significant. Hence, two sample $T$ test showed no significant difference between the two methods.

Pearson correlation of two methods was done and gave a value of 0.978 and $P$ value of $<0.001$. Thus, the two methods are highly positively correlated.

We found few cases (18) with low platelet count on automated analyser which were normal when counted manually. We found one (1) case with very high platelet count (=11 lacs/cumm) on automated counter which were found to be normal on manual counting on PS.

\section{DISCUSSION}

Thrombocyte count is important to evaluate the risk of occurrence of spontaneous bleeding in a patient. If there is confidence in the platelet count values at low levels, it is possible to reduce thrombocyte transfusions to those that are clinically necessary.

In the present study, it is seen that the mean thrombocyte count estimated by the manual method and the automated method for all the samples studied $(n=1000)$ did not show significant statistical difference in the results. The thrombocyte count in the whole blood by using automated haematology analyser and manual method using LS stained peripheral blood smears are $307 \times 10^{3} / \mathrm{uL}$ and $310 \times 10^{3} / \mathrm{uL}$, respectively.

In the similar study Webb et al.12 assessed 35 samples with normal, low, high thrombocyte counts and they compared the smear assessment with the automated counter. Another study which was done cross sectionally conducted in National Centre for Public Health Laboratories of Aden Yemen, Bakhubaira ${ }^{13}$ concluded that the mean thrombocyte count estimated by manual and electronic method was not significantly different, which is showing similarity to our study.

Similarly, study done by Oliveira et al. ${ }^{14}$ concluded, that the low thrombocyte count below $30,000 / \mu$ l obtained in automated haematology counters, should be assessed again by manual method to eliminate chances of error and give precise result. In a study done by De la Salle BJ et al, around $67 \%$ of the automated haematology analyser results were found to be overestimated. Moreover, statistically significant differences in thrombocyte counts were observed in $16.5 \%$ of the cases. 15

In a study Gogoi $G$ et al. showed that the positive predictive value of automated analyser being $52 \%$ and also showed that a large number of cases i.e. 374 samples (9.8\%) labelled as thrombocytopenia (by automated haematology analyser method) is converted to normal thrombocyte range by manual method forming the grey zone area of thrombocytopenia indicating a definite need to examine the blood sample both by automated and manual (PBS and Neubauer chamber counting) method. 16

One study done by Naina et al. showed high prevalence of asymptomatic constitutional macro thrombocytopenia in eastern and north eastern region of India, so using only automated haematology analyser will not be suitable for population of these areas. It is very necessary to recognise and diagnose HPS (Harris Thrombocyte Syndrome), as nearly one out of six persons in certain areas of the Indian subcontinent possess the anomaly. Lack of awareness and miscalculation can create confusion and medical mistakes. During dengue outbreaks when thrombocyte counts fall patients who have HPS are unnecessarily hospitalised. It is also been noted that person with low thrombocyte counts discourage surgeons for surgery, citing that surgical wound will not heal causing grave distress to patients as well as surgeons. 17

Manual thrombocyte counting by using improved Neubauer chamber by phase contrast microscope has been suggested as the reference method which is also the Gold standard for thrombocyte counting available to evaluate any degree of accuracy of the automated haematology count. 18 This method of thrombocyte count along with thrombocyte estimation by the automated haematology analyser are more sensitive but expensive, time consuming and require well equipped laboratory set up with professionals. In contrast, manual thrombocyte estimation method using PBS is simple, cheaper and easier, and does not need any expensive materials and hardly takes 20-25 minutes in laboratories where advanced methods are in scarce, so manual platelet count on PS can be used with high precision. Any abnormal low platelet count on automated analyser should be confirmed by manual examination of PS, as there may be thrombocyte clumping giving wrong results on automated haematology counters.

\section{CONCLUSIONS}

Thrombocyte estimation done manually using PBS is not significantly different from thrombocyte estimation done by automated haematology analysers. Manually done thrombocyte count using PBS can be taken as a simple and rapid method for thrombocyte evaluation in the patients where low thrombocyte count needs an early and immediate attention. This method is simple, rapid as well as cheaper and thus can be done even in centres where automated facility is not available. All the abnormally low or high thrombocyte counts on automated counter must be cross examined manually before being reported.

\section{REFERENCES}

[1] Hartwing HJ. Platelet morphology. In: Loscalzo J, Schafer IA, eds. Thrombosis and haemorrhage. $2^{\text {nd }}$ edn. Blatimore: Williams \& Wilkins 1998: p. 207.

[2] Firkin F, Chesterman C, Penington D, et al. The haemorrhagic disorders. In: De Gruchy's Clinical haematology in medical practice. $5^{\text {th }}$ edn. Oxford: Blackwell Scientific Publications 1989: p. 375-6.

[3] Ogawa M. Differentiation and proliferation of hematopoietic stem cells. Blood 1993;81(11):2844-53.

[4] Behnke 0, Forer A. Blood platelet heterogeneity: evidence for two classes of platelets in man and rat. $\mathrm{Br}$ J Haematol 1993;84(4):686-93.

[5] Zucker MB, Borrelli J. Reversible alterations in platelet morphology produced by anticoagulants and by cold. Blood 1954;9(6):602-8.

[6] Paula ES, Ronald JH. Platelets and megakaryocytes. In: Foerster J, Lukens J, Paraskevos F, eds. Wintrobes clinical haematology. $8^{\text {th }}$ edn. Philadelphia: Lea and Febiger 1981: p. 355-6.

[7] Nurden AT, Nurden P, Sanchez M, et al. Platelets and wound healing. Front Biosci 2008;13:3532-48. 
[8] Brahimi M, Osmani S, Arabi A, et al. The estimation of platelet count from a blood smear on the basis of the red cell: platelet ratio. Turk J Heamtol 2009;26(1):214.

[9] Lozano M, Mahon A, Van der Meer PF, et al. Counting platelets at transfusion threshold levels: impact on the decision to transfuse. A BEST Collaborative UK NEQAS(H) International Exercise. Vox Sang 2014;106(4):330-6.

[10] Phakhounthong K, Chaovalit P, Jittamala P, et al. Predicting the severity of dengue fever in children on admission based on clinical features and laboratory indicators: application of classification tree analysis. BMC Pediatrics 2018;18(1):109.

[11] Milovanovic AT, Stojkovic LM, Dumic I, et al. Diagnostic accuracy of platelet count and platelet indices in noninvasive assessment of fibrosis in nonalcoholic fatty liver disease patients. Canadian Can Article ID 6070135, J Gastroenterol Hepatol 2017;2017:5.

[12] Webb DI, Parker L, Webb K. Platelet count assessment from peripheral blood smear (PBS). Alaska Med 2004;46(4):92-5.
[13] Bakhubaira S. Automated versus manual platelet count in Aden. J Clin Exp Pathol 2013;3(3):149.

[14] Oliveira RA, Takadachi MM, Nonoyama K, et al. Is automated platelet counting still a problem in thrombocytopenic blood? Sao Paulo Med J 2003;121(1):19-23.

[15] De la Salle BJ, McTaggart PN, Briggs C, et al. The accuracy of platelet counting in thrombocytopenic blood samples distributed by the UK National External Quality Assessment Scheme for General Haematology. Am J Clin Pathol 2012;137(1):65-74.

[16] Gogoi G, Kar S, Manta A, et al. The grey zone of thrombocytopenia: accuracy of automated analyser vs manual method. Int Clin Pathol J 2018;6(2):87-90.

[17] Naina HV, Nair SC, Daniel D, et al. Asymptomatic constitutional macrothrombocytopenia among West Bengal blood donors. Am J Med 2002;112(9):742-3.

[18] Anjali SA, Amy S. Platelet function disorder. In: Schulman S, edr. Treatment of Haemophilia. $2^{\text {nd }}$ edn. World Federation of Hemophilia: Wiley-Blackwell 2008: p. 1-3. 